\title{
Patch Antenna Array for Rectenna Application
}

\author{
S.Hemalatha ${ }^{1}$, V.Ganesh ${ }^{2}$, Dr.H.Mangalam ${ }^{3}$ \\ PG Scholar ${ }^{1}$, Assistant Professor ${ }^{2}$, Professor ${ }^{3}$, Department of Electronics and Communication Engineering, \\ Sri Ramakrishna Institute of Technology, Coimbatore. \\ Email: hemalathajk@yahoo.co.in ${ }^{1}$, ganesh.ece@srit.org ${ }^{2}$, mangalam.ece@srit.org ${ }^{3}$
}

\begin{abstract}
Rectenna is a combination of an antenna and a rectifier which is used in Wireless Power Reception and Energy Harvesting applications. The antenna is used to receive RF/Microwave signal and the rectifier is used to convert the received RF/Microwave signal into DC signal. In this work, the design and simulation of the rectangular patch antenna array is carried out at $10 \mathrm{GHz}$ signal frequency for low-profile rectenna applications. Initially a single rectangular patch antenna is designed at $10 \mathrm{GHz}$ frequency using HFSS software. The antenna design parameters are optimized using the electromagnetic simulation software. The inter-element spacing of the antenna is $0.75 \lambda_{0}$. The antenna radiation parameters such as return loss, gain, directivity, efficiency, 2D and 3D radiation patterns, polarization and half power beam width are obtained for single patch and array. From the simulation results, it is observed that the gain and beamwidth of the antenna array is increased and decreased respectively for the increase in elements in the array.
\end{abstract}

Index Terms- Patch antenna, antenna array, rectenna, antenna parameters

\section{INTRODUCTION}

Microstrip antenna was born of microstrip circuit technology and has inherited many characteristics such as low radiating efficiency and narrow bandwidth that are undesirable for a radiator. However, they offered many desirable features in terms of small size, low profile, ease of integration with circuits and forming arrays. Consequently, research has been focused to improve their performance as radiators [3], [6], [7]. Modern mobile communication systems are increasingly employing phased array at base stations to expand the base station customer capacity and reduce interference among adjacent stations. In the wireless industry, such antennas are typically referred as smart or adaptive antenna. Reflector, horn and microstrip array antenna are widely used in microwave applications.

The objective of this work is to design an efficient antenna array for Wireless Power Reception (WPR) and Energy Harvesting (EH) applications. WPR and $\mathrm{EH}$ are achieved using a Rectenna which is a device to convert RF/Microwave power into DC power. A rectenna is a combination of an antenna and rectifier. Antenna is used to receive the RF/Microwave signal and rectifier is used to convert the received $\mathrm{RF} /$ Microwave signal into DC power. Lot of research is being done on the feasibility of powering mobile devices through the harvesting of RF/Microwave signal [1], [2]. The motivation of this project work is to design an efficient harvester i.e., antenna array for the future wireless device with a self powered generator. So, the environment would not be polluted by the disposed battery and the usage of batteries will be limited.

Figure of Merit (FoM) of the rectenna depends on the output DC power, the weight and size of the rectenna. Better value of FoM is achieved when the output power of the rectenna is high and size of the rectenna is low. The output power increases when the size of the antenna array increases. So, there is a tradeoff between output power and size of the rectenna. From antenna theory, the gain of the antenna is directly proportional to the received antenna power. So, in this work, the comparison of gain and area of the antenna are carried out for the antenna and array. Nowadays, Wireless Power Transmission and Reception is an emerging area of research due to enormous developments in wireless communication [4], [5]. In this work, the rectangular microstrip patch antenna array is designed and simulated at $10 \mathrm{GHz}$ frequency for X-band planar, low-profile rectenna applications. The design parameters of single antenna and $2 \times 2$ antenna array are optimized using HFSS Software. The antenna parameters such as return loss, gain, efficiency, directivity, radiation pattern and polarization are obtained using the electromagnetic simulator for the antenna and array.

\section{PATCH ANTENNA}

Design section of a single microstrip patch antenna consists of patch, quarter wave transformer and feedline. A rectangular patch antenna is designed. A $50 \Omega$ surface mount adapter connector is used to connect the feedline to the coaxial cable. The feedline is fed to the patch through a matching network which is a quarter-wave transformer. Fig.1 shows the patch antenna with quarter-wave transformer. The dimensions are calculated based on the transmission line model. The length and width of the patch are calculated using equations (3.1) and (3.2).

$$
L=0.49 \frac{\lambda}{\sqrt{\varepsilon_{r}}}
$$




$$
\begin{aligned}
& \mathrm{W}=\sqrt{\frac{90 \frac{\varepsilon_{r}{ }^{2}}{\varepsilon_{r}-1}}{Z_{A}}} \mathrm{~L} \\
& Z_{1}=\sqrt{Z_{o} R_{\text {in }}}
\end{aligned}
$$

The impedance of the quarter wave line is calculated using equation (3.3). $Z_{1}$ is the transformer characteristic impedance. $Z_{0}$ is the characteristic impedance of the transmission line and $\mathrm{R}_{\mathrm{in}}$ is the edge resistance at resonance. The obtained values for the parameters are illustrated in Fig.1. The return loss of patch antenna is shown in Fig.2.

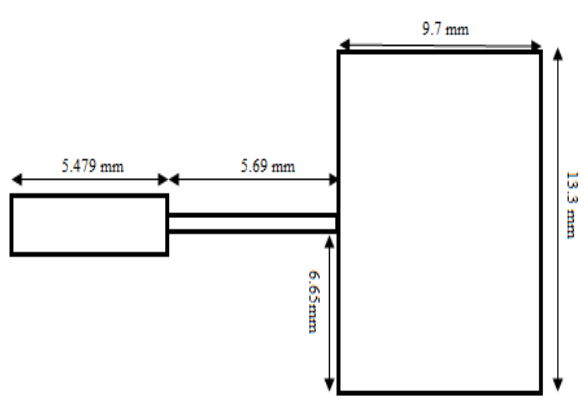

Fig. 1 Patch Antenna Design Layout

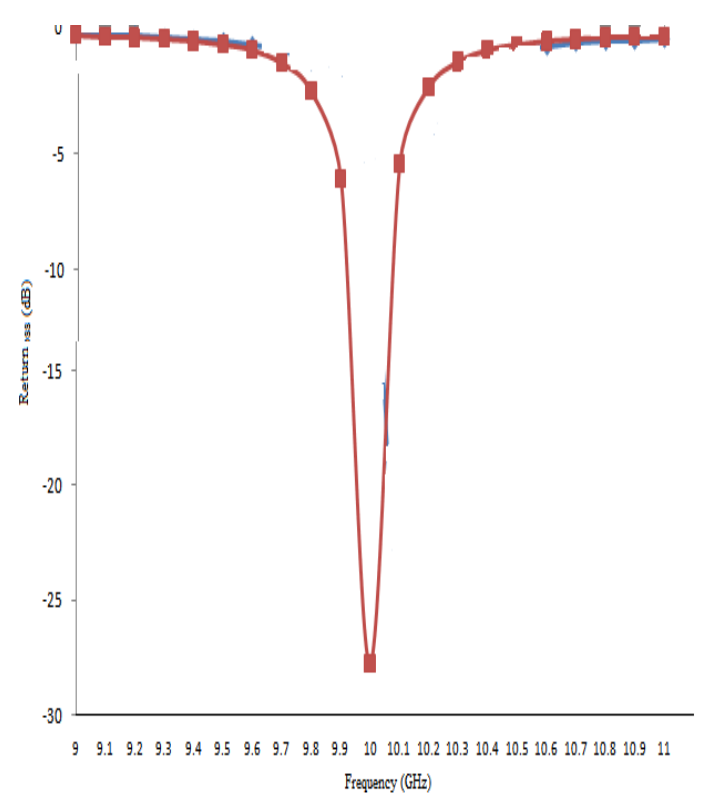

Fig.2 Return Loss of Patch Antenna

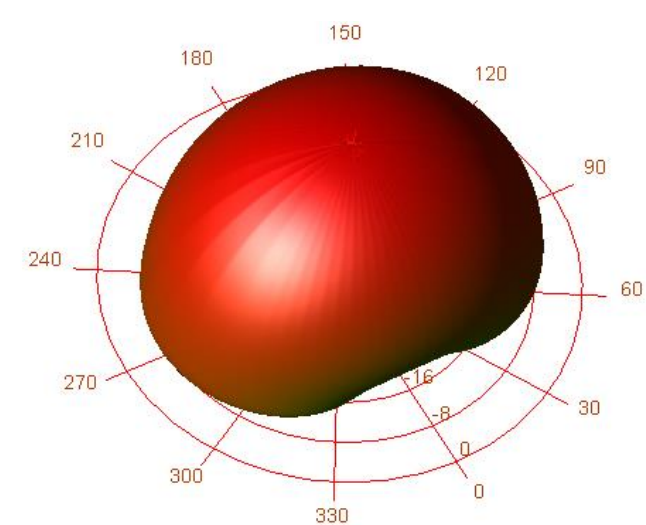

Fig.3 Radiation Pattern of Patch Antenna

The return loss of $-27 \mathrm{~dB}$ is obtained at $10 \mathrm{GHz}$ frequency. The bandwidth of $130 \mathrm{MHz}$ is obtained and the designed antenna has narrow bandwidth with respect to return loss. The gain of $7.07 \mathrm{~dB}$, directivity of $7.82 \mathrm{~dB}$ and efficiency of $84.12 \%$ are obtained for the designed antenna at $10 \mathrm{GHz}$ frequency. The Co and Cross polarizations of E-field are $7.07 \mathrm{~dB}$ and $-34.76 \mathrm{~dB}$ respectively. Similarly, the Co and Cross polarizations of $\mathrm{H}$-field are $7.07 \mathrm{~dB}$ and $-32.86 \mathrm{~dB}$ respectively. The $\mathrm{HPBW}$ of $\mathrm{E}$ and $\mathrm{H}$ plane are $73.95^{\circ}$ and $63.66^{\circ}$ respectively. From the polarization level, it is observed that the antenna is linearly polarized. The 3D radiation pattern of a single rectangular patch antenna is plotted in Fig..3. There is no side lobe and the beamwidth of the radiation pattern is wide in nature.

\section{PATCH ANTENNA ARRAY}

The return loss of $2 \mathrm{X} 2$ rectangular Microstrip patch antenna array is plotted in Fig. 4. The return loss of $-22 \mathrm{~dB}$ is obtained at $10 \mathrm{GHz}$ frequency. The bandwidth of $565 \mathrm{MHz}$ is obtained and the designed array has wider bandwidth. The gain of $11.78 \mathrm{~dB}$, directivity of $12.77 \mathrm{~dB}$ and efficiency of $79.5 \%$ are obtained for the designed array at $10 \mathrm{GHz}$ frequency. The Co and Cross polarizations of E-field are 11.82 $\mathrm{dB}$ and $-22.76 \mathrm{~dB}$ respectively. The Co and Cross polarization of $\mathrm{H}$-field are $12.34 \mathrm{~dB}$ and $-16.53 \mathrm{~dB}$ respectively. From the polarization level, it is observed that the antenna is linearly polarized. The HPBW of $\mathrm{E}$ and $\mathrm{H}$ plane are $35.34^{\circ}$ and $33.80^{\circ}$ respectively. 


\section{Available online at www.ijrat.org}

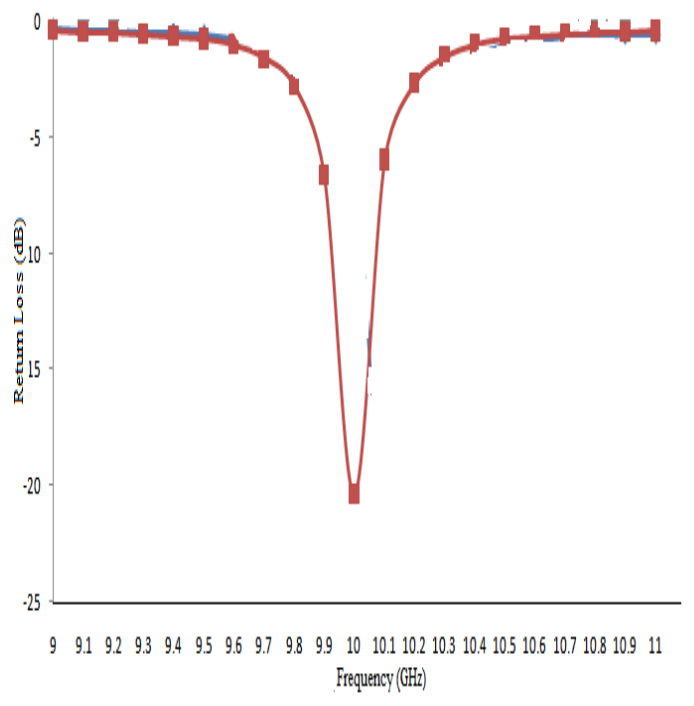

Fig.4 Return Loss of 2X2 Patch Antenna Array

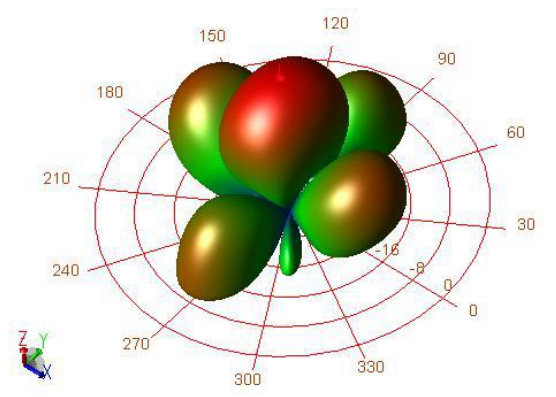

Fig.5 Radiation Pattern of 2X Patch Antenna

The beamwidth of the designed array is decreased and gain is increased compared to the single antenna. The $3 \mathrm{D}$ radiation pattern of $2 \mathrm{X} 2$ rectangular microstrip patch antenna array is plotted in Fig.5. There are four side lobes in the radiation pattern. The comparison of gain, HPBW and area is shown in Table1.

Table 1 Comparison of Gain, HPBW and Area

\begin{tabular}{|c|c|c|c|c|}
\hline Antenna & Gain(dB) & \multicolumn{2}{|c|}{$\begin{array}{c}\text { HPBW } \\
\text { (Degree) }\end{array}$} & $\begin{array}{c}\text { Area } \\
\mathrm{mm}^{2}\end{array}$ \\
\cline { 3 - 4 } & & $\begin{array}{c}\text { E- } \\
\text { Plane }\end{array}$ & $\begin{array}{c}\mathrm{H}- \\
\text { Plane }\end{array}$ & \\
\hline Single & 7.0733 & 73.95 & 63.67 & 506 \\
\hline $2 \times 2$ & 11.78 & 35.34 & 33.80 & 2025 \\
\hline
\end{tabular}

\section{CONCLUSION}

The design and simulation of the rectangular microstrip patch antenna and array have been carried out at $10 \mathrm{GHz}$ signal frequency using HFSS software. Initially a single rectangular patch antenna has been designed and optimized at $10 \mathrm{GHz}$ frequency. The rectangular microstrip patch antenna array of $2 \mathrm{X} 2$ has been designed for the same frequency with inter element spacing of $0.75 \lambda_{0}$. The antenna parameters such as return loss, gain, directivity, efficiency, half power beamwidth, and $\mathrm{Co}$ and Cross polarization of $\mathrm{E}$ and $\mathrm{H}$ planes have been obtained for single antenna and array. The gain of the antenna is increased by increasing the number of antenna elements. The beamwidth of the antenna is decreased by increasing the number of antenna elements. The designed array may be suitable for Rectenna applications.

\section{REFERENCES}

[1] Ali Mavaddat, Seyyed Hossein Mohseni Armaki and Ali Reza Erfanian, 'Millimeter-Wave Energy Harvesting Using 4X4 Microstrip Patch Antenna Array', IEEE Antenna and Wireless Propagation Letter, Vol.14, PP.515-518, 2015.

[2] Hucheng Sun and Wen Geyi, 'A New Rectenna Using Beamwidth-Enhanced Antenna Array for RF Power Harvesting Applications',IEEE Antennas and Wireless Propagation Letters, Vol.16, pp.1451-1454, 2017.

[3] RafalGlogowski, Jean-Francois Zurchur, Custodio Peixeiro and Juan R Mosig, 'A Low-Loss Planar Ka-Band Antenna Subarray for Space Application', IEEE Antennas and Wireless Propagation Letters, Vol.8. PP.1119-1122,2013.

[4] Seung-Tae Khang, Dong-Jin Lee, In-Jun Hwang,Tae-Dong Yeo and Jong- Won Y, 'Microwave Power Transfer With Optimal Number of Rectenna Arrays for Midrange Applications', IEEE Antennas and Wireless Propagation Letters, Vol.17, No.1, PP.155-159, 2018.

[5] Shasa Salsabila, Antrisha Daneraici Setiawan, Atik Charisma, Asep Najmurro Khman and Achmad Munir, 'Design of printed bowtie dipole array antenna for rectenna application', 3rd International Conference on Wireless and Telematics (ICWT), 27-28 July 2017.

[6] Shih-Hsun Hsu, Yu-Jiun Ren and Kai Chang, 'A Dual-Polarized Planar-Array Antenna for s-Band and X-Band Airborne Application', IEEE Antennas and Propagation Magazine, Vol.51, No.4, PP.70-78, 2009.

[7] Wang, H., Huang, X.B. and Fang, D.G., 'A Single Layer Wide Band U-Slot Microstrip Patch Antenna Array', IEEE Antennas and Wireless Propagation Letters, Vol.7,PP.9-12, 2008. 